\title{
VARIAÇÃO GENÉTICA PARA COMPOSTOS BIOQUÍMICOS EM SEMENTES DE UMA POPULAÇÃO NATURAL DE Luehea divaricata MART.
}

\author{
Ricardo de Oliveira Manoel ${ }^{1}$, Patrícia Ferreira Alves ${ }^{2}$, Marcela Aparecida de Moraes ${ }^{3}$, \\ Janaína Rodrigues da Silva ${ }^{4}$, Maiara Ribeiro Cornacini ${ }^{4}$, José Luis Susumu Sasaki ${ }^{5}$, Mário \\ Luiz Teixeira de Moraes ${ }^{5}$, Maria de Lourdes Teixeira de Moraes Polizeli ${ }^{6}$
}

\footnotetext{
${ }^{1}$ Biológo, Doutor em Agronomia - Sistemas de Produção na Faculdade de Engenharia - UNESP Campus de Ilha Solteira (SP), rickom.is@gmail.com

${ }^{2}$ Engenheira Agronôma, Pós-Doutoranda em Agronomia - Sistemas de Produção na UNESP Campus de Ilha Solteira (SP).

${ }^{3}$ Engenheira agronôma, Doutoranda em Agronomia - Sistemas de Produção na UNESP Campus de Ilha Solteira (SP).

${ }^{4}$ Bióloga, Mestranda em Agronomia - Sistemas de Produção na UNESP Campus de Ilha Solteira (SP).

${ }^{5}$ Professor do Departamento de Fitotecnia, Tecnologia de Alimentos e Sócio Economia na UNESP Campus de Ilha Solteira (SP).

${ }^{6}$ Professora Associada do Departamento de Biologia, Faculdade de Filosofia, Ciências e Letras - USP Campus de Ribeirão Preto (SP).
}

RESUMO: Espécies arbóreas, pelo seu grande porte e longevidade, são os organismos chaves dos ecossistemas florestais. Dentre as espécies florestais no Brasil, encontra-se a açoita-cavalo (Luehea divaricata Mart.), uma espécie arbórea, heliófita e hermafrodita, muito utilizada na medicina popular. $\mathrm{O}$ estudo da composição bioquímica de sementes florestais é muito importante para a obtenção de informações sobre a espécie e para o delineamento de estratégias de conservação. O objetivo deste trabalho foi quantificar a variação genética para caracteres bioquímicos (teores de proteínas, carboidratos e amido) das sementes e determinar o ganho genético a partir da seleção de árvores provenientes de uma população natural de L. divaricata. A população de polinização livre está localizada na área de empréstimo da Fazenda de Ensino, Pesquisa e Extensão da Faculdade de Engenharia de Ilha Solteira (FEIS/UNESP), no município de Selvíria - MS. Foram coletadas aleatoriamente sementes de 12 árvores matrizes para análises de composição química, visando à determinação de caracteres bioquímicos. A partir destes, foram estimados os parâmetros genéticos e estatísticos, e para isto, foi utilizado o delineamento de blocos ao acaso, com 12 tratamentos (árvores matrizes), quatro repetições e uma planta por parcela. A população apresentou variação genética para os caracteres bioquímicos. Os maiores valores de herdabilidade média entre as progênies foram encontrados para os caracteres bioquímicos prolamina $(0,98)$ e albumina $(0,95)$, portanto serão as características que responderam mais facilmente à seleção. Portanto, a presente população de L. divaricata apresentou ampla base genética, sendo promissora a sua utilização em programas de conservação e melhoramento genético.

Palavras-chave: Açoita-cavalo. Composição química. Parâmetros genéticos. Sementes florestais.

Cultura Agronômica, Ilha Solteira, v.24, n.1, p.53-62, 2015 


\section{GENETIC VARIATION FOR BIOCHEMICAL COMPOUNDS IN SEEDS OF A NATURAL POPULATION OF Luehea divaricata MART.}

ABSTRACT: Tree species because of its large size and longevity are the key organisms of forest ecosystems. Among the tree Brazilian species, açoita-cavalo (Luehea divaricata Mart.), is the heliophytic and hermaphrodite tree species, widely used in folk medicine. The study of the biochemical composition of forest seeds is very important for obtaining information about the species and for the delineation of conservation strategies. The aim of this study was to quantify the genetic variation for biochemical characters (protein, carbohydrates and starch) of seeds and determine the genetic gain from the selectied trees of a natural population of $L$. divaricata. The open-pollinated population is located in the lended area of the Education Farm, Research and Extension, Faculty of Engineering of Ilha Solteira (FEIS / UNESP) from Selvíria - MS. Seeds were randomly collected from 12 seed trees for analysis of chemical composition, aiming to determine the biochemical compounds. From these, genetic and statistical parameters were determined, for this, a randomized block design was used, with 12 treatments (mother trees), four replications and one plant per plot. The population presented genetic variation for the biochemical characters. The most values of median heritability among progenies were find to biochemical characters prolamina (0.98) e albumina (0.95), therefore are the characteristics that answered more readily to selection. Therefore, this population of $L$. divaricata presented a wide genetic base, which makes them promising to be used in conservation and breeding programs.

Key words: Açoita-cavalo. Chemical composition. Genetic parameters. Forest seeds.

\section{INTRODUÇÃO}

O conhecimento da composição química e nutricional de sementes em espécies arbóreas é imprescindível para se avaliar a disponibilidade de nutrientes que as sementes possuem, principalmente, em ambientes com alto grau de antropização. Dessa forma, ter esse conhecimento em uma população natural de uma espécie arbórea é fundamental para se avaliar as possibilidades de utilização desta população em programas de conservação e melhoramento genético.

Dentre os componentes químicos presentes em uma semente destacam-se as proteínas e os carboidratos; esta composição é definida geneticamente, podendo ocorrer influência de fatores ambientais (CARVALHO; NAGAKAWA, 2000; SATTLER et al., 2004).

Estudos de variabilidade genética para caracteres bioquímicos de espécies arbóreas típicas do Cerrado, por exemplo, bioma este particularmente objeto de uma enorme pressão antrópica foram realizados por Alves (2003) que analisou a composição proteica em sementes de uma população natural de jatobá-do-cerrado (Hymenae stignocarpa Mart.), por Bonjorno (2006), que analisou a composição proteica em sementes de duas populações naturais de jenipapo (Genipa americana L); por Alves (2006) que estudou sementes de uma população natural de lixeira (Curatella americana L.) e por Arantes (2007) que avaliou a

Cultura Agronômica, Ilha Solteira, v.24, n.1, p.53-62, 2015 
variação genética e composição química em sementes de uma população de canafístula (Peltophorum dubium (Sprengel) Taubert).

A seleção de indivíduos tem sido uma tarefa difícil, uma vez que os caracteres de importância, em sua maioria são quantitativos e, por isto, apresentam base genética complexa, além de serem bastante influenciados pelo ambiente. Geralmente estes caracteres estão inter-relacionados em magnitude e sentido variáveis, de tal forma que a seleção em um provoca uma série de mudanças em outros. Assim, a quantificação de ganhos e a identificação de materiais genéticos superiores para novos ciclos de seleção são de fundamental importância para o melhoramento genético. Neste contexto, a utilização de índices torna-se indispensável pela sua abrangência e pelos fundamentos teóricos em que se baseiam (CRUZ, 2001).

A espécie L. divaricata Mart., popularmente conhecida como açoita-cavalo, é amplamente distribuída no território brasileiro. Trata-se de uma espécie arbórea, hermafrodita e polinizada por abelhas, destacando-se, principalmente, a espécie Apis melifera. Suas folhas são comercializadas por conta de suas características fitoterápicas relativamente a problemas de saúde tais como disenteria, leucorréia, reumatismo, blenorragia e tumores. Ademais, a infusão das suas flores é utilizada contra bronquite e, por fim, sua raiz é depurativa (TANAKA et al., 2003). Com relação à composição química desta espécie, pouco se sabe e, em virtude disto, o objetivo deste trabalho foi quantificar a variação genética para caracteres bioquímicos das sementes e determinar o ganho genético a partir da seleção de árvores proveniente de uma população natural como base para programas de conservação e melhoramento genético.

\section{MATERIAL E MÉTODOS}

As sementes de L. divaricata utilizadas nas análises de composição química realizadas neste trabalho, visando à determinação de caracteres bioquímicos (teores de proteínas, carboidratos e amido), foram colhidas no mês de novembro de 2002, em 12 árvores de polinização livre, na Fazenda de Ensino, Pesquisa e Extensão da Universidade Estadual Paulista (FEIS/UNESP), no município de Selvíria, no estado de Mato Grosso do Sul.

Esta população se caracteriza por estar localizada em uma região com alto grau de perturbação antrópica, em função da pecuária de corte e de solo severamente acidentado, em razão de a localidade ter sido utilizada, no passado, como área de empréstimo pela Companhia Energética de São Paulo (CESP), para fins da extração de sedimentos para construção da Barragem da Usina Hidrelétrica de Ilha Solteira, SP.

O solo da Fazenda Experimental foi classificado por Demattê (1980) como Latossolo Vermelho Distrófico típico argiloso a moderado hipistrófico, álico, caulinítico, férrico, compactado, muito profundo, moderadamente ácido (LVd) e relevo classificado como moderadamente plano e ondulado. O clima da região, segundo a classificação de Köppen, é do tipo Aw, definido como tropical úmido com estação chuvosa no verão e seca no inverno. A temperatura média anual é de $24,5^{\circ} \mathrm{C}$, precipitação média anual de $1.232 \mathrm{~mm}$ e umidade 
relativa média anual de 64,8\% (HERNANDEZ et al., 1995).

As análises das sementes foram realizadas no Laboratório de Genética de Populações e Silvicultura, do Departamento de Fitotecnia, Tecnologia de Alimentos e Sócio-Economia, da Faculdade de Engenharia de Ilha Solteira, da Universidade Estadual Paulista "Júlio de Mesquita Filho" (UNESP). A composição química das sementes foi obtida determinando-se os seguintes constituintes:

a) Teor de amido (AMI, $\mathrm{mg}^{-1}$ ): foi determinado tendo por base os procedimentos de Thivend et al. (1972) e Magalhães (1991), utilizando-se de uma curva padrão de glicose (0-1 mg/mL), e leitura realizada no espectrofotômetro a $505 \eta \mathrm{m}$;

b) Teor de carboidratos totais (CHO, $\mathrm{mg} \mathrm{g}^{-1}$ ): foi obtido pelo método de fenolsulfúrico, de acordo com Dubois et al. (1956), utilizando-se uma curva padrão de manose $(0-0.5 \mathrm{mg} / \mathrm{mL})$, sendo que as leituras foram realizadas em espectrofotômetro a $490 \eta \mathrm{m}$; e

c) Teor de proteínas (albumina-ALB, prolamina-PRO, glutelina-GLU e globulina-GLO, $\mathbf{m g ~ g}^{-1}$ ): obtido pelo método descrito por Sturgis et al. (1952), modificado de acordo com o trabalho de Garcia-Agustin e Primo-Millo (1989), sendo que as leituras foram realizadas no espectrofotômetro a $660 \eta \mathrm{m}$.

As estimativas de parâmetros estatísticos e genéticos para os caracteres avaliados foram obtidas pelo método REML/BLUP (máxima verossimilhança restrita / melhor predição linear não viciada), empregando-se o software genético-estatístico SELEGEN, desenvolvido por Resende (2007). Os teores de amido, carboidratos totais e proteínas foram designados como caracteres bioquímicos e utilizou-se o delineamento experimental de blocos ao acaso, com 12 tratamentos (árvores matrizes), quatro repetições e uma planta por parcela, conforme o modelo estatístico:

$$
\mathrm{y}=\mathrm{Xr}+\mathrm{Zg}+\mathrm{e}
$$

em que: y: vetor de dados; r: vetor dos efeitos de repetição (assumidos como fixos) somados à média geral; g: vetor dos efeitos genotípicos (assumidos como aleatórios); e: vetor de erros ou resíduos (aleatórios). As letras maiúsculas representam as matrizes de incidência para os referidos efeitos. Esse modelo equivale a um teste de clones não aparentados.

\section{RESULTADOS E DISCUSSÃO}

Verificou-se a existência de variação genética entre as árvores matrizes para todos os caracteres bioquímicos estudados (Tabela 1), evidenciados pela significância do teste da razão de verossimilhança (LRT) a $1 \%$ de probabilidade para todos os caracteres, indicando que existem diferenças genéticas entre as árvores matrizes e, portanto, a possibilidade de obter ganhos genéticos pela seleção das árvores matrizes mais produtivas.

Cultura Agronômica, Ilha Solteira, v.24, n.1, p.53-62, 2015 
A população natural de L. divaricata, apresentou coeficiente de variação experimental baixo para todos os caracteres estudados, os quais variaram de 2,04\% (PRO) a 10,06\% (CHO), o que indica precisão nas estimativas obtidas para todos os caracteres estudados (Tabela 1). Abdala et al. (2002) avaliando sementes de Myracrodruon urundeuva em uma população natural, encontraram para todos os caracteres bioquímicos analisados valores abaixo de $10 \%$. Neste contexto, Oliveira et al. (2009) encontraram em média para duas populações analisadas de Genipa americana coeficientes de variação experimental menor que $11,48 \%$.

Com relação aos tipos de proteínas, a população natural de L. divaricata apresentou maior valor de globulina $\left(57,67 \mathrm{mg} \mathrm{g}^{-1}\right)$, seguida de glutelina $\left(46,70 \mathrm{mg} \mathrm{g}^{-1}\right)$, albumina $\left(44,20 \mathrm{mg} \mathrm{g}^{-1}\right)$ e prolamina $\left(5,90 \mathrm{mg} \mathrm{g}^{-1}\right)$. Resultados semelhantes foram encontrados por Pinto et al. (2005) que encontraram predomínio de globulina $\left(146,10 \mathrm{mg} \mathrm{g}^{-1}\right)$, seguida de glutelina (16,9 $\left.\mathrm{mg} \mathrm{g}^{-1}\right)$, prolamina $\left(13,1 \mathrm{mg} \mathrm{g}^{-1}\right)$ e albumina $\left(13,1 \mathrm{mg} \mathrm{g}^{-1}\right)$, para sementes de Bauhinia variegata. Já Oliveira et al. (2009), avaliando duas populações de Genipa americana, encontraram predomínio de albumina (44,38 e 40,81 $\mathrm{mg} \mathrm{g}^{-1}$ ), seguida de glutelina $\left(40,73\right.$ e $\left.25,49 \mathrm{mg} \mathrm{g}^{-1}\right)$, globulina $\left(25,21\right.$ e $\left.14,75 \mathrm{mg} \mathrm{g}^{-1}\right)$ e prolamina $(7,50$ e 3,55 $\mathrm{mg} \mathrm{g}^{-1}$ ). Abdala et al. (2002) verificaram para sementes de $M$. urundeuva maior valor para glutelina (118,0 a 286,0 $\left.\mathrm{mg} \mathrm{g}^{-1}\right)$, seguida de prolamina (60,0 a 135,2 $\left.\mathrm{mg} \mathrm{g}^{-1}\right)$, albumina (35,0 a $107,3 \mathrm{mg}$ g-1) e globulina (3,4 a 9,3 $\left.\mathrm{mg} \mathrm{g}^{-1}\right)$. Enquanto Santos (2004), analisando os mesmos quatro tipos de proteínas verificou predominância de glutelina $\left(41,28 \mathrm{mg} \mathrm{g}^{-1}\right)$, seguida de albumina $\left(27,13 \mathrm{mg} \mathrm{g}^{-1}\right)$, globulina $\left(11,59 \mathrm{mg} \mathrm{g}^{-1}\right)$ e prolamina $\left(7,10 \mathrm{mg} \mathrm{g}^{-1}\right)$. Faria et al. (2004), avaliando sementes de Bauhinia forficata, verificaram a predominância de globulina $\left(8,93 \mathrm{mg} \mathrm{g}^{-1}\right)$, seguida de glutelina $\left(6,69 \mathrm{mg} \mathrm{g}^{-1}\right)$, prolamina $\left(2,62 \mathrm{mg} \mathrm{g}^{-1}\right) \mathrm{e}$ albumina $\left(1,39 \mathrm{mg} \mathrm{g}^{-1}\right)$.

Para os teores de amido e carboidrato, as médias foram de 1,10 e $26,02 \mathrm{mg} \mathrm{g}^{-1}$, respectivamente (Tabela 1). Bonjorno (2006) e Arantes (2007) obtiveram resultados semelhantes para as médias de amido e carboidrato, $2,47 \mathrm{mg} \mathrm{g}^{-1} ; 2,60 \mathrm{mg} \mathrm{g}^{-1}$ e 31,71 $\mathrm{mg} \mathrm{g}^{-1}$; $55,96 \mathrm{mg} \mathrm{g}^{-1}$, respectivamente. Santos (2004) verificou teores médios de carboidrato de 7,46 $\mathrm{mg}^{-1}$ e amido de $0,55 \mathrm{mg}^{-1}$. Souza et al (2012) encontraram teores de amido e carboidrato, respectivamente, para algumas espécies: Hymenaea courbaril $\left(3,80 \mathrm{mg} \mathrm{g}^{-1} \mathrm{e}\right.$ $\left.381,53 \mathrm{mg} \mathrm{g}^{-1}\right)$, Mezilaurus itauba (5,61 $\mathrm{mg} \mathrm{g}^{-1}$ e 81,13 $\left.\mathrm{mg} \mathrm{g}^{-1}\right)$, Byrsonima lancifolia (8,9 $\mathrm{mg} \mathrm{g}^{-1}$ e 31,46 $\left.\mathrm{mg} \mathrm{g}^{-1}\right)$, Apeiba tibourbou $\left(9,2 \mathrm{mg} \mathrm{g}^{-1}\right.$ e 72,24 $\mathrm{mg} \mathrm{g}^{-1}$ ) e Eschweilera ovata $\left(36,77 \mathrm{mg} \mathrm{g}^{-1}\right.$ e $\left.19,08 \mathrm{mg} \mathrm{g}^{-1}\right)$ quase todos superiores aos encontrados em L. divaricata.

As estimativas do coeficiente de variação genética $\left(C V_{g}\right)$ para a população natural de L. divaricata, apresentou maiores valores para amido (16,03\%) e glutelina $(11,31 \%)$, e os menores valores para prolamina $(6,85 \%)$ e albumina $(8,30 \%)$. Os maiores valores para amido e glutelina indicam boa base genética na população para ambos os caracteres bioquímicos. Bonjorno (2006) e Oliveira et al. (2009), avaliando sementes de duas populações de G. americana, obtiveram resultados semelhantes com maior valor para amido $(22,86 \%)$ e menor valor para prolamina $(16,44 \%)$. Os $C V_{g}$ observados foram relativamente de média magnitude para todos os caracteres bioquímicos, evidenciando a existência de 
variação genética nas sementes da população natural estudada (Tabela 1). A variação genética detectada pode estar relacionada com o grau da ação antrópica em que a população natural esteve submetida no passado.

As estimativas de herdabilidade são ferramentas importantes nos trabalhos de melhoramento, pois expressam a variabilidade genética disponível na população, proporcionando o conhecimento da magnitude relativa das variações genéticas e ambientais (WRIGHT, 1976). No presente estudo, os maiores valores de herdabilidade média entre as progênies foram encontrados para os caracteres bioquímicos prolamina $(0,98)$ e albumina $(0,95)$, portanto serão as características que responderam mais facilmente à seleção. Na literatura alguns trabalhos apresentam o mesmo comportamento para os mesmos caracteres bioquímicos, como os observados em Alves (2003, 2006) e Arantes (2007). Aguiar et al. (2001) avaliando as características fisiológicas de sementes de Astronium fraxinifolium, e Canuto et al. (2008), avaliando os caracteres nutricionais em sementes de Dipteryx alata, obtiveram estimativas de herdabilidade alta para todas as características estudadas. Porém, Wall e Corgan (1999) encontraram estimativas de herdabilidade que variaram de 0,30 a 0,64 para o conteúdo de sólidos solúveis em células.

Tabela 1. Estimativas da herdabilidade média entre as progênies $\left(h_{m}^{2}\right)$, coeficiente de variação genética $\left(C V_{g}\right)$, a razão do $C V_{g} / C V_{e}\left(C V_{r}\right)$, coeficiente de variação experimental $C V_{e}$, ganhos genéticos $\left(G_{s}\right)$, acurácia $\left(r_{\hat{a} a}\right)$, média $(\hat{m})$ e qui-quadrado da deviance $\left(\chi^{2}\right)$ para os teores de amido, carboidrato e proteínas (albumina, globulina, prolamina, glutelina), em sementes de uma população natural de L. divaricata.

\begin{tabular}{lcccccccc}
\hline Caracteres & $h_{m}^{2}$ & $C V_{g}(\%)$ & $C V_{r}$ & $C V_{e}(\%)$ & $\hat{G}_{s}(\%)$ & $r_{\hat{a} a}$ & $\hat{m}$ & LRT $\left(\chi^{2}\right)$ \\
\hline Amido $\left(\mathrm{mg} \mathrm{g}^{-1}\right)$ & 0,94 & 16,03 & 2,05 & 7,83 & 12,28 & 0,97 & 1,10 & $35,93^{*}$ \\
Carboidrato $\left(\mathrm{mg} \mathrm{g}^{-1}\right)$ & 0,75 & 8,77 & 0,87 & 10,06 & 5,53 & 0,87 & 26,02 & $9,45^{*}$ \\
\hline Proteínas & & & & & & & & \\
\hline Albumina $\left(\mathrm{mg} \mathrm{g}^{-1}\right)$ & 0,95 & 8,30 & 2,26 & 3,66 & 5,84 & 0,97 & 44,20 & $45,29 *$ \\
Globulina $\left(\mathrm{mg} \mathrm{g}^{-1}\right)$ & 0,94 & 8,77 & 2,01 & 4,35 & 3,35 & 0,97 & 57,67 & $39,38^{*}$ \\
Prolamina $\left(\mathrm{mg} \mathrm{g}^{-1}\right)$ & 0,98 & 6,85 & 3,36 & 2,04 & 5,53 & 0,99 & 5,90 & $65,54^{*}$ \\
Glutelina $\left(\mathrm{mg} \mathrm{g}^{-1}\right)$ & 0,86 & 11,31 & 1,24 & 9,14 & 5,18 & 0,93 & 46,70 & $217,74^{*}$ \\
\hline
\end{tabular}

LRT: Teste da Razão de Verossimilhança.

A razão $C V_{g} / C V_{e}\left(C V_{r}\right)$ foi superior a 1 para todos os caracteres com exceção do $\mathrm{CHO}$, o que indica uma situação muito favorável à seleção (Tabela 1), sendo que o caráter mais indicado para a seleção é o teor de prolamina $(3,36)$ e o menos indicado é o teor de carboidrato $(0,87)$. A indicação dos teores de prolamina como o caráter mais favorável para a seleção também é corroborado pela maior estimativa da acurácia $(0,99)$ que é a relação entre o valor genético predito e o verdadeiro. Os ganhos genéticos estimados foram de $12,28 \%$ (AMI), 5,84\% (ALB), 5,66\% (CHO), 5,53\% (PRO), 5,18\% (GLU) e 3,35\% (GLO), que corresponde a uma nova média de $70,85 \mathrm{mg} \mathrm{g}^{-1}, 46,78 \mathrm{mg} \mathrm{g}^{-1}, 27,50 \mathrm{mg} \mathrm{g}^{-1}, 6,22 \mathrm{mg} \mathrm{g}^{-}$ 1, 49,11 $\mathrm{mg} \mathrm{g}^{-1}$ e $1,23 \mathrm{mg} \mathrm{g}^{-1}$, respectivamente. 
Como resultado das perturbações antrópicas esperava-se que estas alterações resultassem no efeito de bottleneck, ou seja, na redução do tamanho efetivo da população e, consequentemente, na redução da variabilidade genética da população decorrente do aumento do parentesco entre os poucos indivíduos remanescentes na região. No entanto, observou-se que as árvores desta população de $L$. divaricata apresenta variação genética para os caracteres estudados e substancial controle genético nos caracteres para ser explorada pela seleção na região do município de Selvíria, MS, onde está localizada a população natural. Além disto, essa variabilidade genética pode ser explorada pela seleção das melhores árvores para os caracteres, visando a conservação genética in situ e ex situ e para o melhoramento genético da espécie, com destaque para a seleção do teor de amido, por apresentar maior ganho estimado com a seleção.

\section{CONCLUSÕES}

A população natural de $L$. divaricata apresentou variação genética para todos os caracteres bioquímicos estudados (teores de carboidratos, amido e proteínas: albumina, prolamina, glutelina e globulina). Este resultado é muito importante, pois devido ao alto grau de perturbação antrópica, como a pecuária de corte e do solo severamente acidentado, era esperado a redução da variabilidade genética da população remanescente como decorrência do efeito de gargalo genético. Contudo, os resultados permitiram-nos recomendar a utilização da espécie em programas de conservação e de melhoramento genético, sendo o caráter teor de amido o mais indicado por apresentar o maior ganho estimado com a seleção.

\section{AGRADECIMENTOS}

Gostaríamos de agradecer ao Conselho Nacional de Desenvolvimento Científico e Tecnológico $(\mathrm{CNPq})$ pelas bolsas de produtividade em pesquisa concedida aos docentes Mário L. T. Moraes e Maria L. T. M. Polizeli e bolsa de doutorado concedida à Marcela A. Moraes. Agradecemos à Coordenação de Aperfeiçoamento de Pessoal de Nível Superior (CAPES) pela bolsa de doutorado concedida à Patrícia F. Alves e à Fundação de Amparo à Pesquisa do Estado de São Paulo (FAPESP) pelo apoio de uma bolsa de doutorado concedida a Ricardo O. Manoel, na Faculdade de Engenharia de Ilha Solteira/ UNESP (Brasil). Gostaríamos de agradecer a José L. S. Sasaki pela colaboração nas análises realizadas, à Janaína R. Silva e Maiara R. Cornacini, pela colaboração nas análises laboratoriais.

\section{REFERÊNCIAS BIBLIOGRÁFICAS}

ABDAlA, L.; MORAES, M. L. T.; RECHIA, C. G. V.; GIORGINI, J. F.; SÁ, M. E.; POLIZELI, M. L. T. M. Biochemical traits useful for the determination of genetic variation in a natural population of Myracrodruon urundeuva. Pesquisa Agropecuária Brasileira, Brasília, v. 37, n. 7, p.909-916, 2002. 
AGUiAR, A. V.; BORTOlOZO, F. R.; MORAES, M. L. T.; SÁ, M. E. Determinação de parâmetros genéticos em população de gonçalo-Alves (Astronium fraxinifolium) através das características fisiológicas da semente. Scientia Forestalis, Piracicaba, v. 1, n. 60, p.89-97, 2001 .

ALVES, S. G. Variabilidade genética, germinação, repetibilidade e composição química de sementes em progênies de jatobá-do-cerrado (Hymenaea stigonocarpa Mart. ex Hayne). 2003. 34 f. Trabalho de Conclusão de Curso (Graduação em Agronomia) Faculdade de Engenharia de Ilha Solteira, Universidade Estadual Paulista, Ilha Solteira, 2003.

ALVES, P. F. Variabilidade genética para compostos bioquímicos de sementes em uma população natural de Curatela americana L. 2006. 38 f. Trabalho de Conclusão de Curso (Graduação em Agronomia) - Faculdade de Engenharia de Ilha Solteira, Universidade Estadual Paulista, Ilha Solteira, 2006.

ARANTES, F. C. Autocorrelação espacial, variação genética e composição química em sementes de uma população natural de Peltophorum dubium (Sprengel) Taubert. 2007. 39 f. Trabalho de Conclusão de Curso (Graduação em Agronomia) - Faculdade de Engenharia de Ilha Solteira, Universidade Estadual Paulista, Ilha Solteira, 2007.

BONJORNO, I. I. Variação genética para compostos bioquímicos em sementes de populações naturais de Genipa americana L. 2006. 58 f. Trabalho de Conclusão de Curso (Graduação em Agronomia) - Faculdade de Engenharia de Ilha Solteira, Universidade Estadual Paulista, Ilha Solteira, 2006.

CANUTO, D. S. O.; SILVA, A. M.; MORAES, M. A.; SILVA, C. L. S. P.; MORAES, M. L. T.; SÁ, M. E. Variabilidade genética de populações naturais de Dipteryx alata Vog. por meio de caracteres nutricionais em sementes. Revista do Instituto Florestal, São Paulo, v. 20, n. 2, p.89-97, 2008.

CARVALHO, N. M.; NAKAGAWA, J. Sementes: ciência, tecnologia e produção. Jaboticabal: FUNEP, 2000. 588 p.

CRUZ, C. D. Programa Genes: versão Windows; aplicativo computacional em genética e estatística. Viçosa: Editora UFV, 2001. 648 p.

DEMATTÊ, J. L. I. Levantamento detalhado dos solos do Campus experimental de Ilha Solteira. Piracicaba, ESALQ / USP, 1980. 114 p.

DUBOIS, M.; GILlES, K. A.; HAMILTON, J. K.; REBERS, P. A.; SMITH, F. Colorimetric method for determination of sugar and related substances. Analytical Chemistry, Washington, v. 28, n. 3, p.350-356, 1956. 
FARIA, R. A. P. G.; ANDRADE-NETO, M.; PINTO, L. S.; CASTELlÓN, R. R.; CALVETE, J. J.; CAVADA, B. S. Caracterização química parcial e bioquímica de sementes de Bauhinia forficata Link. Archivos Latinoamericanos de Nutrición, Caracas, v. 54, n. 3, p.349-353, 2004.

GARCIA-AGUSTIN, P.; PRIMO-MILLO, E. Ultrastructural and biochemical changes in cotyledon reserve tissues during germination of citrus seeds. Journal of Experimental Botany, Oxford, v. 40, n. 3, p.383-390, 1989.

HERNANDEZ, F. B. T.; LEMOS FILHO, M. A. F.; BUZETTI, S. Software HIBRISA e o balanço hídrico de Ilha Solteira. Ilha Solteira: UNESP / FEIS, 1995. 45 p. (UNESP / FEIS -Área de Hidráulica e Irrigação. Série Irrigação, 1).

MAGALHÃES, M. M. Desenvolvimento e carboidratos constituintes do fruto de jaboticaba (Myrciaria jaboticaba Berg. cv. "Sabará"). 1991. 77 f. Dissertação (Mestrado em Ciências de Alimentos) - Universidade Federal de Viçosa, Viçosa, 1991.

OLIVEIRA, S. A.; BONJORNO, I. I.; ALVES, P. F.; MORAES, M. A.; FREITAS, M. L.; MORAES, M. L. T.; POLIZELI, M. L. T. M. Variação genética para compostos bioquímicos em sementes de duas populações naturais de Genipa americana L.: 1- análises individuais e univariada. Scientia Forestalis, Piracicaba, v. 37, n. 81, p.71-78, 2009.

PINTO, L. S.; ANDRADE NETO, M.; BACARIN, M. A.; CASTELlÓN, R. R.; GADELHA, T. S.; GADELHA, C. A.; CAVADA, B. S. Caracterização química e bioquímica de sementes de Bauhinia variegata L. Revista Brasileira de Engenharia Agrícola e Ambiental, Campina Grande, v. 9, n. 3, p.385-290, 2005.

RESENDE, M. D. V. Software SELEGEN - REML/BLUP: Sistema estatístico e seleção genética computadorizada via modelos lineares misto. Colombo: Embrapa Florestas, 2007. $359 \mathrm{p}$.

SANTOS, E. B. R. Variabilidade genética em uma população de umbuzeiro (Spondias tuberosa Arruda) através de caracteres bioquímicos da semente. 2004. 20 f. Trabalho de Conclusão de Curso (Graduação em Agronomia) - Faculdade de Engenharia de Ilha Solteira, Universidade Estadual Paulista, Ilha Solteira, 2004.

SATTLER, S. E.; GILlILAND, L. U.; LUNDBACK, M. M.; POLLARD, M.; DELLAPENNA, D. Vitamin $\mathrm{E}$ is essential for seed longevity and for preventing lipid peroxidation during germination. The plant Cell, Waterbury, v. 16, n. 6, p.1419-1432, 2004.

SOUZA, L. C. D.; SÁ, M. E.; MORAES, S. M. B.; CARVALHO, M. A. C.; SILVA, M. P.; ABRANTES, F. L. Composição química e nutrientes em sementes das espécies florestais

Cultura Agronômica, Ilha Solteira, v.24, n.1, p.53-62, 2015 
pente de macaco, flor de paca, itaúba, jatobá e murici manso. Bioscience Journal, Uberlândia, v. 28, n. 3, p.478-483, 2012.

STURGIS, F. E.; MIEARS, R. J.; WALKER, R. K. Protein in rice as influenced by variety and fertilizer levels. Louisiana Experimental Station Technical Bulletin, Louisiana, p.1466, 1952.

TANAKA, J. C. A.; VIDOTTI, G. J.; SILVA, C. C. A New tormentic acid derivative from Luehea divaricata Mart. (Tiliaceae). Journal of the Brazilian Chemical Society, São Paulo, v. 14, n. 3, p.475-478, 2003.

THIVEND, P.; MERCIER, C.; GUILBOT, A. Determination of starch with glucoamylase methods carbohydrate chemisty. New York, Academic, v. 2, n. 6, p.100-105, 1972.

WALL, A. D.; CORGAN, J. N. Heritability estimates and progeny testing of phenotypic selections for soluble solids content in dehydrator onion. Euphytica, Berlim, v. 106, n. 1, p.7-13, 1999.

WRIGHT, J. W. Introduction to Forest genetics. New York: Academic Press, 1976, 464 p. 